\title{
Resource distribution, growth and strategies for enhancing fish production in north-eastern states of India
}

\author{
PIYASHI DEBROY ${ }^{1}$, M. KRISHNAN ${ }^{1}$, ANIL D. UPADHYAY ${ }^{2}$, V. RAMASUBRAMANIAN ${ }^{1}$ \\ KEITH R. CRIDDLE ${ }^{3}$, V. R. KIRESUR ${ }^{4}$ AND SAMAR K. DATTA ${ }^{5}$ \\ ${ }^{1}$ ICAR Central Institute of Fisheries Education (Deemed University), Mumbai - 400 061, Maharashtra, India \\ ${ }^{2}$ College of Fisheries, Central Agricultural University, Lembucherra - 799 210, Tripura, India \\ ${ }^{3}$ School of Fisheries and Ocean Science, University of Alaska Fairbanks, Alaska, AK 99801 \\ ${ }^{4}$ College of Agriculture, University of Agricultural Sciences, Bijapur, Karnataka - 586 101, India \\ ${ }^{5}$ Centre for Management in Agriculture, Indian Institute of Management, Ahmedabad - 380 015, India \\ e-mail: piyashi.debroy@gmail.com
}

\begin{abstract}
Contribution of the eight north-eastern states of India towards national fish production is only $5.9 \%$ despite the vast resources available in the region. There is a clear disparity in the total fish production vis- $a$-vis the potential in these states of India. This paper estimates the growth and instability of fish production in the north-eastern states of India relating the performance to the resource availability in the region and suggests strategies for enhanced fish production. Compound growth rates and Coppock's instability index were used to determine the growth and performance of fish production in these states. Assam emerged as the state producing the maximum quantity of fish among the eight north-eastern states during the period 1999-2010. The share of Tripura was $16 \%$ and only $13 \%$ of the total fish production was contributed by the other six states. In terms of productivity, Manipur followed by Tripura and Mizoram head the table. There is considerable scope for improving the performance of fisheries sector in the north-eastern states of India by adoption of appropriate technologies and up-scalable models.
\end{abstract}

Keywords: ARIMA, Fisheries, Growth trend analysis, North-east India

\section{Introduction}

The total fish production in India for the year 2012 was 8.67 million $\mathrm{t}$ (DAHDF, 2013). This comprised contributions from both the inland and the marine fisheries sector. There are perceptible areas where inland fish production especially freshwater aquaculture has made significant impact. The north-eastern (NE) region of India comprises many important fishery resources in the country and in fact, ranks $6^{\text {th }}$ among the top 25 biodiversity hotspots in the world (Kottelat and Whitten, 1996; Gurumayum and Choudhury, 2009). The fisheries sector in the NE region of India holds an important position in the socio-economic and cultural context of the people in the region. However, the contribution of the $\mathrm{NE}$ region to the fisheries sector inspite of the presence of the vast fisheries resources in the region is only nearly 5.9\% (DAHDF, 2013). A cursory examination of the data on fish production at the national level clearly indicates a disparity in the total fish production vis-a-vis the potential of the same in a given area. This paper attempts to assess (i) the relative fisheries resource distribution and (ii) growth and instability of fish production in NE states of
India; as well as (iii) to develop strategies for enhanced fish production in the NE region of India.

\section{Materials and methods}

Fish production statistics of North-eastern Development Finance Corporation Ltd. were used for the study. Trend lines were used for analysing the observed fish production in all the states of North-east India. The different trend lines used in this study are based on the criteria of the best fit for the data.

Compound growth rate (CGR) was estimated with the standard Cobb-Douglas type function $\mathrm{Y}=\mathrm{AX}_{\mathrm{I}}^{\mathrm{bi}-1}$ and $\mathrm{r}=\operatorname{antilog}(\beta-1) \times 100$.

Coppock's instability index (CII) was used to measure the instability in fish production in each of the NE states and also for the NE region as a whole (Coppock, 1962). This was measured by fitting a log-linearised exponential time trend using the formula: |anti $\operatorname{In} \sqrt{\operatorname{In}} V-1 \mid X 100$, where, $\operatorname{InV}=\frac{1}{n-1}\left[\sum\left(\operatorname{In} Y_{t+1}-\operatorname{In} Y_{t}\right)\right]-\frac{1}{n-1}\left[\sum\left(\operatorname{In} Y_{t+1}-\operatorname{In} Y_{t}\right)\right]$

Growth performance and instability studies have also been used by Jeyanthi and Nikita (2012) to analyse 
the CGR, market concentration and instability indices of Indian scampi export and by Krishnan et al. (1994) to capture the trends in the growth of marine products exports in the context of newly introduced liberalisation policies in the country. Studies in analysing the CGR and instability indices in the scenario of Indian agriculture across spatial and temporal scales have been reported by Larson et al. (2004); Prajneshu and Chandran (2005); Chand and Raju (2008 a,b) as well as Reddy (2009) and the same in the milk production sector in Gujarat by Shah and Dave (2010).

Forecasting fish production till the year 2015 was done using SPSS (Version 16) through Time Series Expert Modeler with ARIMA, Simple, Holt and Brown models and Microsoft Excel (2007) program.

\section{Results and discussion}

\section{Resource availability}

North-eastern states of India abound with pristine water bodies whose potential for fish production has been barely tapped. The potential of fish production in NE states of India is estimated to be 4.88 lakh t. A total of 5.63 lakh ha of water spread area is available for fish production in the eight NE states of India excluding the riverine resources (Table 1). This comprises 0.33 lakh ha of reservoir water spread area, 3.71 lakh ha of water spread in tanks and ponds and 1.59 lakh ha of flood plains and derelict water bodies. Arunachal Pradesh alone has 3.18 lakh ha of water spread area followed by Assam with 1.35 lakh ha. The riverine resources alone comprises $20,875 \mathrm{~km}$ of water resources (Table 2). Meghalaya has $5600 \mathrm{~km}$ of rivers followed by Assam $(4820 \mathrm{~km})$ and Manipur $(3360 \mathrm{~km})$.

The NE states contributed 3.14 lakh $\mathrm{t}$ of fish during the period 2010-2011 (Table 3). This signifies a substantial increase in fish production in the region by as much as 1 lakh t over a period of 10 years (Fig. 1). It can be seen from Table 3 that the total fish production was only 2.2 lakh $t$ in the region during 1999-2000. The extent
Table 2. Riverine resources of the NE states of India

\begin{tabular}{ll}
\hline State & Rivers and canals $(\mathrm{km})$ \\
\hline Arunachal Pradesh & 2000 \\
Assam & 4820 \\
Manipur & 3360 \\
Meghalaya & 5600 \\
Mizoram & 1395 \\
Nagaland & 1600 \\
Sikkim & 900 \\
Tripura & 1200
\end{tabular}

Source: NEDFI Databank, 2013

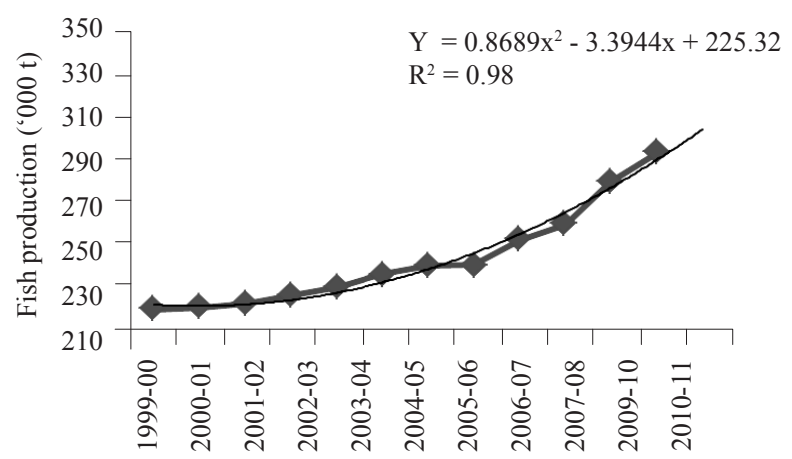

Fig. 1. Trend in fish production in NE region of India

of disparity in the performance of fish production across the eight states is evident from the fact that $72 \%$ of the total fish production in 2010-11 was from Assam, while Tripura contributed $16 \%$ and the other six states together contributed $13 \%$.

Table 4 gives the trend in fish productivity in the eight NE states of India during 1999-2010. The data excludes the output from riverine systems. It can be seen that productivity is maximum for Manipur with an output of $17.80 \mathrm{t}$ per ha of water spread area (WSA), followed by Tripura with $17.21 \mathrm{t}$ and Mizoram with $16.37 \mathrm{t}$.

One of the major issues in analysing data for fish production in NE states of India is the fact that there appears to be substantial discrepancies and inconsistencies in the available data.

Table 1. Fishery resources of the NE states of India excluding the riverine resources

\begin{tabular}{lllll}
\hline State & $\begin{array}{l}\text { Reservoirs } \\
\text { (lakh ha) }\end{array}$ & $\begin{array}{l}\text { Tanks and ponds } \\
\text { (lakh ha) }\end{array}$ & $\begin{array}{l}\text { Flood plain lakes and } \\
\text { derelict water bodies (lakh ha) }\end{array}$ & $\begin{array}{l}\text { Total water bodies } \\
\text { (lakh ha) }\end{array}$ \\
\hline Arunachal Pradesh & 0.00 & 2.76 & 0.42 & 3.18 \\
Assam & 0.02 & 0.23 & 1.10 & 1.35 \\
Manipur & 0.01 & 0.05 & 0.04 & 0.10 \\
Meghalaya & 0.08 & 0.02 & 0.00 & 0.10 \\
Mizoram & 0.00 & 0.02 & 0.00 & 0.02 \\
Nagaland & 0.17 & 0.50 & 0.00 & 0.67 \\
Sikkim & 0.00 & 0.00 & 0.03 & 0.03 \\
Tripura & 0.05 & 0.13 & 0.00 & 0.18 \\
\hline
\end{tabular}

Source: NEDFI Databank, 2013 
Table 3. Fish production (' $000 \mathrm{t}$ ) in the NE states of India

\begin{tabular}{|c|c|c|c|c|c|c|c|c|c|c|c|c|}
\hline State & 1999-00 & $2000-01$ & 2001-02 & 2002-03 & 2003-04 & 2004-05 & 2005-06 & 2006-07 & 2007-08 & 2008-09 & 2009-10 & $2010-11$ \\
\hline Arunachal Pradesh & 2.40 & 2.50 & 2.60 & 2.60 & 2.65 & 2.70 & 2.75 & 2.77 & 2.83 & 2.88 & 2.65 & 3.04 \\
\hline Assam & 159.77 & 158.62 & 161.45 & 165.52 & 181.00 & 186.31 & 188.00 & 181.48 & 190.32 & 200.15 & 218.82 & 227.24 \\
\hline Manipur & 15.51 & 16.05 & 16.45 & 16.60 & 17.60 & 17.80 & 18.22 & 18.61 & 18.60 & 18.80 & 19.20 & 20.20 \\
\hline Meghalaya & 4.68 & 6.18 & 4.97 & 5.37 & 5.15 & 5.64 & 4.12 & 5.49 & 4.00 & 3.96 & 4.21 & 4.56 \\
\hline Mizoram & 2.89 & 2.86 & 3.15 & 3.25 & 3.38 & 3.68 & 3.75 & 3.76 & 3.76 & 2.89 & 3.04 & 2.90 \\
\hline Nagaland & 5.00 & 5.50 & 5.20 & 5.50 & 5.56 & 4.90 & 5.50 & 5.80 & 5.80 & 6.18 & 6.36 & 6.59 \\
\hline Sikkim & 0.14 & 0.14 & 0.14 & 0.14 & 0.14 & 0.14 & 0.15 & 0.15 & 0.18 & 0.17 & 0.17 & 0.18 \\
\hline Tripura & 29.34 & 29.42 & 29.45 & 29.52 & 17.98 & 19.84 & 23.87 & 28.63 & 36.25 & 36.00 & 42.27 & 49.23 \\
\hline Total & 219.73 & 221.27 & 223.41 & 228.50 & 233.46 & 241.01 & 246.36 & 246.69 & 261.74 & 271.03 & 296.72 & 313.93 \\
\hline
\end{tabular}

Source: NEDFI Databank, 2013

Table 4. Productivity trends in fish production in NE India (1999-2010)

\begin{tabular}{lll}
\hline State & $\begin{array}{l}\left(\text { WSA }^{*}\right) \\
(\text { lakh ha })\end{array}$ & $\begin{array}{l}\text { Productivity } \\
\left(\mathrm{t} \mathrm{ha}^{-1} \mathrm{WSA}\right)\end{array}$ \\
\hline Arunachal Pradesh & 3.18 & 0.084 \\
Assam & 1.35 & 13.69 \\
Manipur & 0.10 & 17.80 \\
Meghalaya & 0.10 & 4.86 \\
Mizoram & 0.02 & 16.37 \\
Nagaland & 0.67 & 0.84 \\
Sikkim & 0.03 & 0.51 \\
Tripura & 0.18 & 17.21
\end{tabular}

${ }^{*}$ WSA: Water spread area

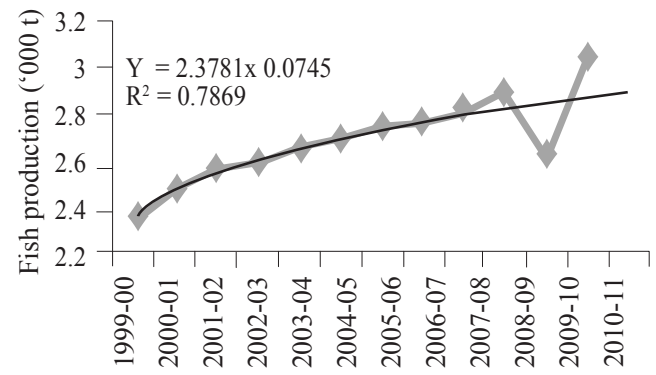

(a)

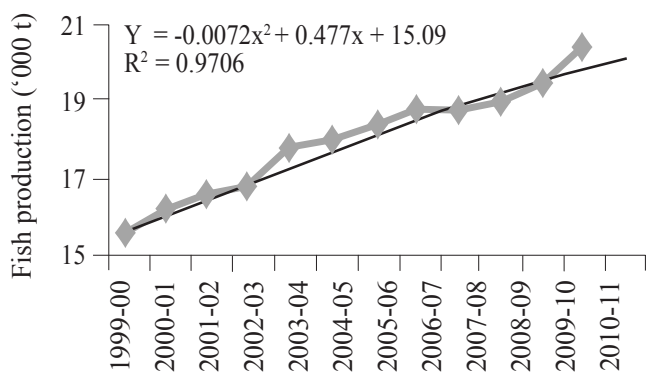

(c) resources with golden mahseer (Tor putitora) as the state fish. It can be observed (Fig. 2a) that the power function gave the best fit to the data of fish production in Arunachal Pradesh. This function described $78 \%$ of the variation in fish production over time. Fish production in Arunachal Pradesh showed consistent improvement over the period from 1995 to 2011. Using the forecasting feature in SPSS (Version 16), it can be seen that fish production in Arunachal Pradesh is likely to grow from the current production of 3.03 thousand $t$ registering a modest growth rate of $310 \mathrm{t}$ over the period of next four years in absolute terms (Fig. 4a).

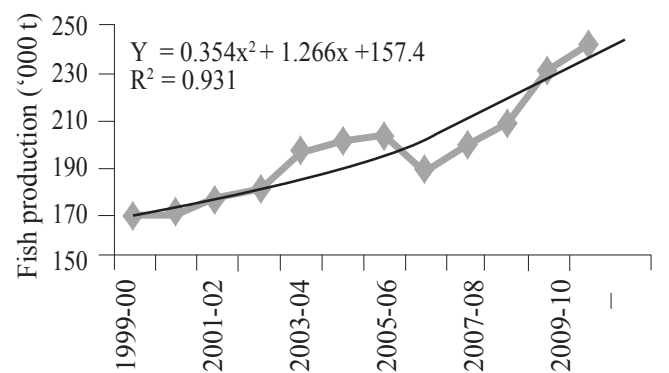

(b)

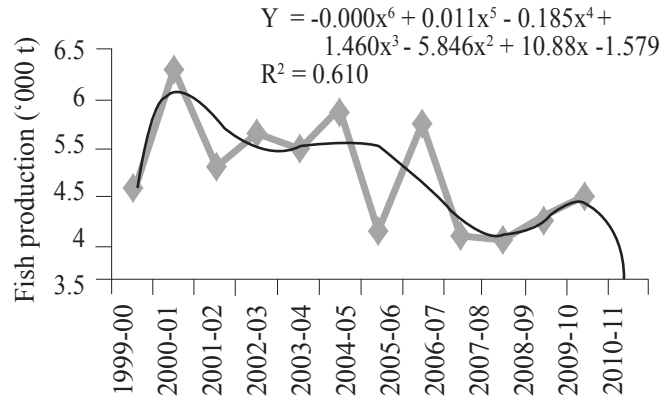

(d)

Fig. 2. Trends in fish production in different states of the North-eastern region of India. (a) Arunachal Pradesh, (b) Assam, (c) Manipur, (d) Meghalaya

Arunachal Pradesh is characterised by a hilly terrain with lakes in the middle and higher belts and beels in the lower belts. Aquatic resources are spread over an area of 7,000 ha which comprise $30-40 \%$ of cold water aquatic
In the case of Assam, the trend in fish production was amenable to the polynomial trend line of degree 2 which explained as much as $93 \%$ of the variation in fish production with respect to time (Fig. 2b). The forecasted 
growth in absolute terms was 257 thousand $t$ in the year 2015- 6 compared to 227 thousand $t$ in 2010-11, indicating an increase in fish production by 30,000 thousand $t$ within subsequent four years (Fig. 4b). Comparing the resource availability and performance in absolute terms, it can be seen that the performance of Assam in fish production was to a large extent more efficient compared to that of Arunachal Pradesh over the same period of time. This can be attributed to the role played by Assam State Department of Fisheries which has been actively involved in implementing various unique schemes such as commercialisation of indigenous fish for entrepreneurship development, development of model fishermen villages, initiation of organic fish farming with certification, involvement of para-fishery extension workers, women empowerment through fisheries, implementation of Assam Fish Seed Rules (2010) and the proposal to set up the marketing wing of the State Department of Fisheries.

Manipur is endowed with abundant fishery resources such as ponds, tanks, lakes (particularly the Loktak Lake), marshy and swampy areas, rivers, reservoirs, submerged cropped lands and low lying paddy fields. The fisheries of Manipur is also popular for its state fish pengba (Osteobrama belangiri). Even though the area under aquaculture is presently 18,600 ha, the state falls short with respect to fish production and this shortage is met from Assam, West Bengal and Andhra Pradesh. Though in absolute terms, the fish production of Manipur was low, the polynomial trend line of degree 2 explained as much as $97 \%$ of the variation in fish production in Manipur (Fig. 4c). The forecasted fish production indicated that there would be an additional production of about 1.5 thousand $t$ over the period from 2011 to 2015 (Fig. 3b). Therefore, in comparison with the two big states of Arunachal Pradesh and Assam, Manipur seems to have performed relatively better in terms of productivity per ha of water spread area.

The absolute figures in respect of fish production in Meghalaya varied from only 3.96 thousand $t$ in 2008-09 to 6.18 thousand $\mathrm{t}$ in the year 2000-01 (Fig. 2d). The substantial variation in fish production of Meghalaya is clearly brought out by the fact that a polynomial trend line of degree 4 gave the best fit explaining about $60 \%$ of the variation in fish production in Meghalaya over time. The forecasted figures for fish production in Meghalaya indicated only a marginal increase of $360 \mathrm{t}$ over the period 2010-11 to 2015-16 (Fig. 4d). With the aim to fulfill the state demand with respect to fish consumption, the Meghalaya State Aquaculture Mission set up the first fish seed eco-hatchery unit under private ownership in the year 2012 .

The performance of Mizoram in fish production is also abysmally poor in spite of the state being endowed with considerable stretches of plain area conducive for development of fisheries. Out of 24,000 ha of potential area for aquaculture, only 4,000 ha has been utilised till 2010-11. The state fish is nghavang (Semiplotus

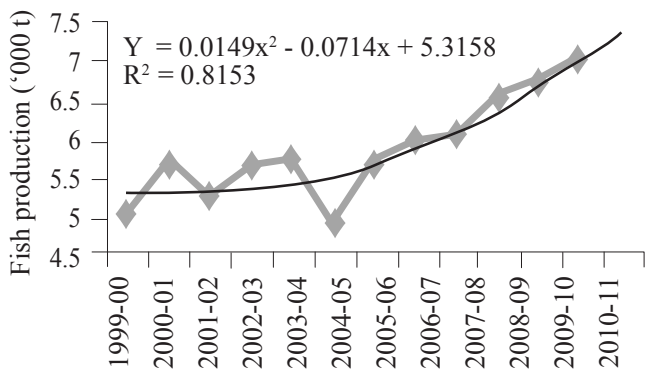

(b)

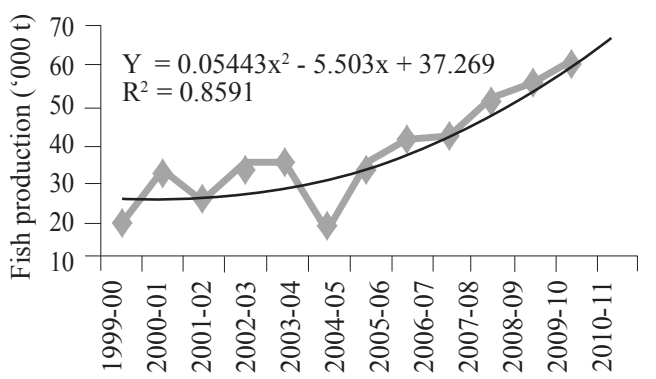

(d)

Fig. 3. Trends in fish production in the states of (a) Mizoram, (b) Nagaland, (c) Sikkim, (d) Tripura in NE India 


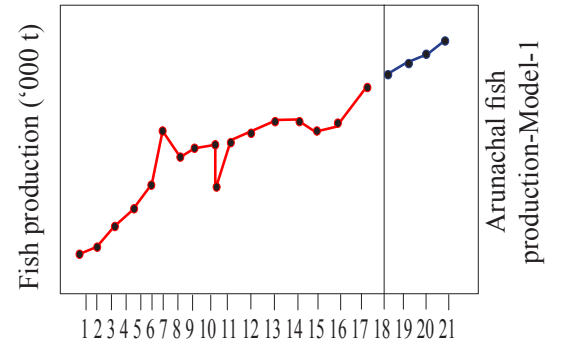

(a)

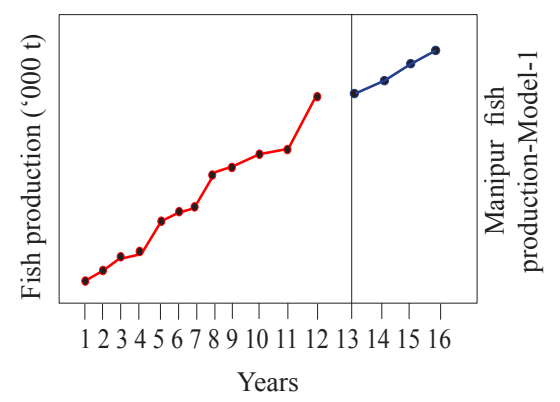

(c)

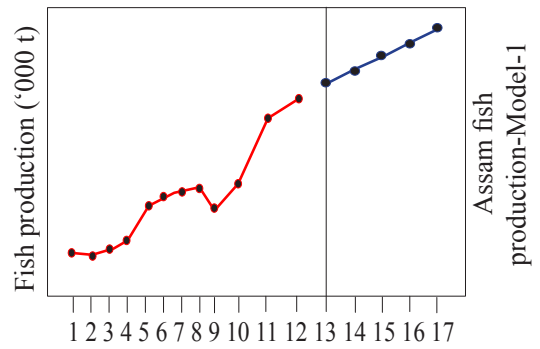

(b)

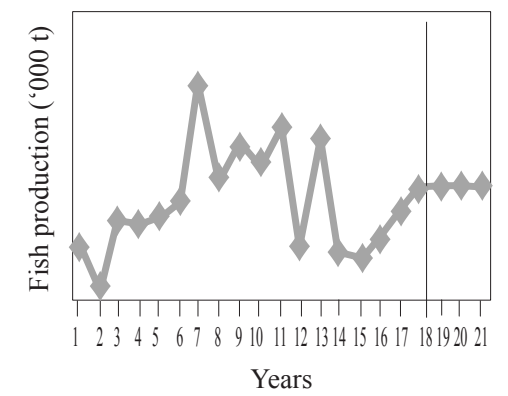

(d)

- Observed, — Forecast

Fig. 4. Predicted fish production of (a) Arunachal Pradesh, (b) Assam, (c) Manipur, (d) Meghalaya

modestus). Mizoram aims to achieve self-sufficiency in fish production by the end of the $12^{\text {th }}$ five year plan. The variation in the data is quite obvious and the polynomial curve of degree 2 explained $71 \%$ of the variation in fish production of Mizoram (Fig. 3a). As in the case of Meghalaya, the forecasted fish production of Mizoram is expected to increase by only 510 t over the period 2010-11 to 2015-16 (Fig. 5a).

With the present utilisation of fishery resources at $4.5 \%$ of the 30,000 ha of the lentic resources, performance of Nagaland in fish production varied from 4,900 $t$ in 2004-05 to 6,580 t in 2010-11 (Fig. 3b). The state fish is chocolate mahseer (Neolissochilus hexagonolepis). Fish production trend in Nagaland has been captured by the polynomial trend line of degree 2 which explained as much as $82 \%$ of the variation of fish production in the state over the period of time. In comparison to Meghalaya and Mizoram, the forecasted fish production of Nagaland appears to be on a better footing and is expected to record an additional $500 \mathrm{t}$ over the period from 2010-11 to 2015-16 (Fig. 5b).

Fish production of Sikkim shows inconsistency and could be attributed to erroneous recording of data. Fish production in Sikkim ranged from 140 to $180 \mathrm{t}$ only between the periods 1999 to 2011 (Fig. 3c). Though the absolute increase in fish production in Sikkim was marginal, it is surprising that the exponential function has given the best fit to the data, explaining as much as 78\% of the variation in fish production with respect to time.
Data inconsistency being so obvious in the case of fish production in Sikkim, the forecasted fish production is only as reliable as the base data. Fish production in Sikkim is expected to increase from $180 \mathrm{t}$ in $2010-11$ to $200 \mathrm{t}$ in 2015-16 (Fig. 5c).

Tripura is a high achiever among the eight NE states of India. This is more so when compared to the resource availability in the state. Fish production in Tripura varied from $1798 \mathrm{t}$ in 2003-04 to $4923 \mathrm{t}$ in 2010-11 (Fig. 3d). This high performing state has overcome certain inconsistencies in data in the initial years used for this analysis; but perusal of recorded data after 2003-04 showed a significant increasing trend. These inconsistencies of the initial years appear to have played a major role and a polynomial trend line of degree 2 gave the best fit to fish production in Tripura and explained $86 \%$ of the total variation in fish production in Tripura for the period considered. It may be noted that the data would be showing an exponential trend line if the trend line were fitted to the data for the period 2003-04 to 2010-11. The predicted fish production in Tripura also showed a substantial increase in absolute terms over the period 2010-11 to 2015-16 (Fig. 5d). Fish production in Tripura could rise as much as 2,683 t during this period of time.

The total fish production in NE states of India varied from $219,000 \mathrm{t}$ in 1999 to $313,000 \mathrm{t}$ in $2010-11$. This performance of fish production in NE India has been aptly captured by the polynomial trend line of degree 2 which has explained $98 \%$ of the variation in fish production 


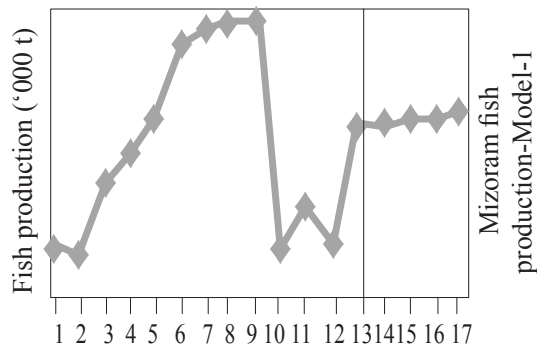

(a)

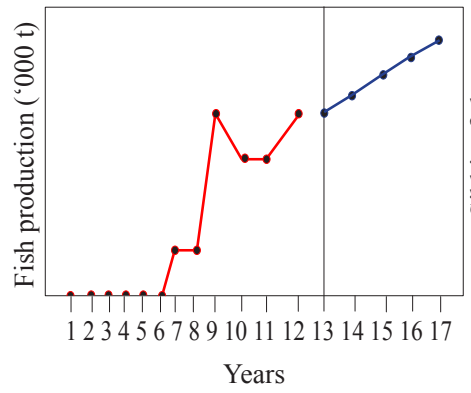

(c)

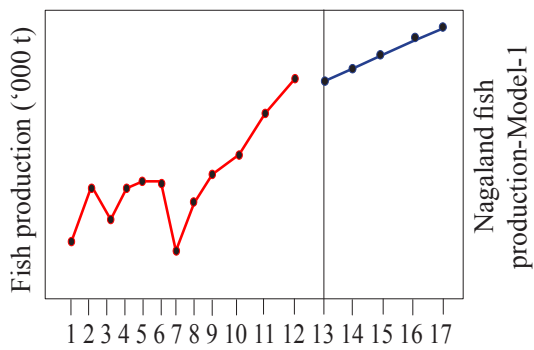

(b)

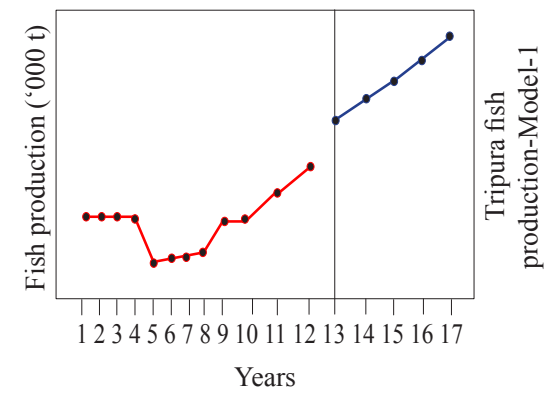

(d)

— Observed, - Forecast

Fig. 5. Predicted fish production of (a) Mizoram, (b) Nagaland, (c) Sikkim and (d) Tripura

with respect to time (Fig.1). It is expected to increase to $406,000 \mathrm{t}$ in the year 2015, indicating an absolute increase in fish production by as much as 92,000 t (Fig. 6).

Several things need to be kept in mind before taking a final stand on the trends in fish production in NE states of India. The forecasted fish production in the NE states of India relies on expectations vis-a-vis the potentiality of the resources that are available in the region. Furthermore, there is much to be desired in respect of the standardisation of methodology as well as organised compilation, tabulation and publication of fisheries statistics.

Fig. 7 shows that the CGR and CII of the different NE states of India. The state of Tripura lies in the zone of high growth and high instability in contrast to the state of Mizoram which lies in the zone of low growth and low instability. However, a low instability index does not indicate a desirable situation with respect to the performance in fish

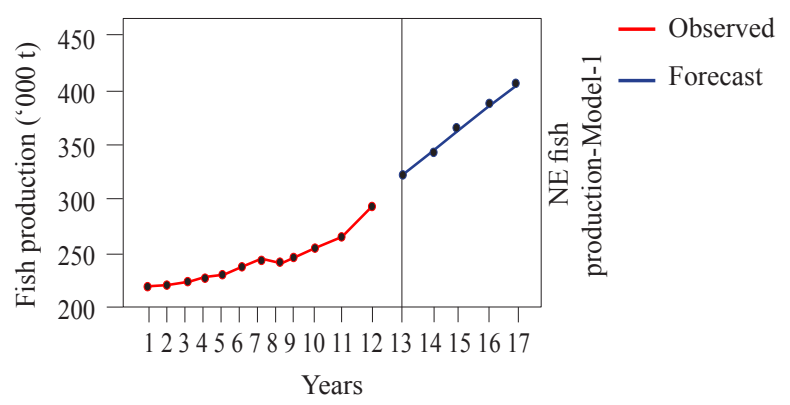

Fig. 6. Predicted fish production in the NE region of India production as in the case of Mizoram which showed meager growth in terms of fish production in spite of being relatively stable with low CII in comparison to the other states. This is clearly observed in the case of Tripura, which registered the highest growth in fish production despite having high instability index. The states of Arunachal Pradesh, Assam, Sikkim, Manipur and Nagaland were found to be in the medium range of growth-instability and Meghalaya lay close to Mizoram in terms of growth $v s$ instability.

Even though there are vast fishery resources across the whole NE region of India, the opportunities to harness and utilise these resources are still untapped in many of

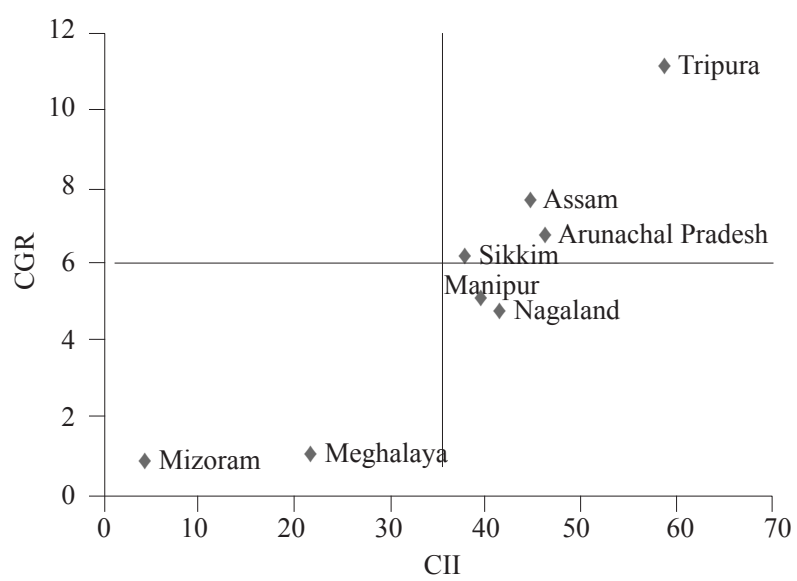

Fig. 7. Compound growth rate (CGR) vs Coppock's instability index (CII) of fisheries of the NE States of India 
the states (Sarkar and Ponniah, 2006). It is again a matter of fact that sustainable utilisation of these resources requires that the constraints crippling the $\mathrm{NE}$ region including inadequacies in infrastructure, communications, technology and transportation need to be sorted out. This would enhance and strengthen the institutional functioning and networking in fisheries. Further, there is a need to attract private investments in the fisheries sector in the region for sustainable utilisation of resources, replenishment of stocks wherever overexploited, proper functioning of the present hatcheries and stopping destructive fishing methods such as dynamite poisoning (Gurumayum and Choudhury, 2009). This is very important for ensuring the sustainability of fisheries through appropriate policies which would otherwise result in instability owing to inconsistent growth oriented policies (Fauzi and Anna, 2012). Strengthening of the required database and resource mapping through GIS and remote sensing to carry out suitable research and development activities in the NE fisheries sector are the important issues that need to be addressed at present as the information available is limited only to the potential of the North-east with respect to cultivable, sport and ornamental fishes (Sarkar and Ponniah, 2006). Since the NE region of India is home to different tribes in the region, the socio-economically disadvantaged tribal people can greatly benefit from the subsidised schemes of the Department of Animal Husbandry Dairying and Fisheries (DAHDF), New Delhi for development of freshwater aquaculture.

The NE region of India shares its borders with international boundaries with the countries Bangladesh, Bhutan, China, Myanmar, and Nepal. This can be used to the advantage of boosting foreign trade with fish and fishery products from the region. Since majority of the population in the NE region are fish eaters, there is an urgent need for the entire region to be self-sufficient in fish production.

\section{References}

Chand, R. and Raju S. S. 2008a. Instability in Andhra Pradesh agriculture - A disaggregate analysis. Agric. Econ. Res. Rev., 21: 283-288.

Chand, R. and Raju S. S. 2008b. Instability in Indian agriculture during different phases of technology and policy. Discussion Paper: NPP 01/2008, National Centre for Agricultural Economics and Policy Research, Indian Council of Agricultural Research, New Delhi, 17 pp.

Coppock, J. D. 1962. International economic instability, McGraw-Hill, New York.

DAHDF 2013. Annual Report 2012-13, Department of Animal Husbandry, Dairying and Fisheries, Ministry of Agriculture, Government of India, New Delhi.

Fauzi, A. and Anna, Z. 2012. Growth and instability of small pelagic fisheries of the North Coast of Java, Indonesia: Lesson learned for fisheries policy. China - USA Business Review, 11(6): 739-748.

Gurumayum, S. D. and Choudhury, M. 2009. Fishing methods in the rivers of North-east India. Indian J. Trad. Knowledge, 8: $237-241$.

Jeyanthi, K. and Nikita Gopal 2012. Growth and instability in Indian frozen scampi export. Fish. Technol., 49: 187-192.

Krishnan, M., Ravisankar, T. and Sharma, B. M. 1994. Development prospects of marine products export from India. Indian J. Agric. Marketing, Conf. Spcl., 39-45.

Kottelat, M. and Whitten, T. 1996. Freshwater biodiversity in Asia with special reference to fish, World Bank Technical Paper No. 343, The World Bank, Washington, DC, p. 17-22.

Larson, D. W., Jones, E., Pannu, R. S. and Sheokand, R. S. 2004. Instability in Indian agriculture - a challenge to the green revolution technology. Food Policy, 29: 257-273.

Prajneshu and Chandran, K. P. 2005. Computation of compound growth rates in agriculture: Revisited. Agric. Econ. Res. Rev., 18: 317-324.

Reddy Amarender, A. 2009. Growth and instability in chickpea production in India: A state level analysis, Agricultural Situation in India, p. 230-145.

Sarkar, U. K. and Ponniah, A. G. 2006. Evaluation of Northeast Indian fishes for their potential as cultivable, sport and ornamental fishes along with their conservation and endemic status. In: Ponniah, A. G. and Sarkar, U. K. (Eds.), Fish biodiversity of North-east India. National Bureau of Fish Genetic Resources, Lucknow.

Shah, J. and Dave. D. 2010. Regional trends and pattern in milk production and drivers for future growth in Gujarat State. Agric. Econ. Res. Rev., 23: 295-302. 